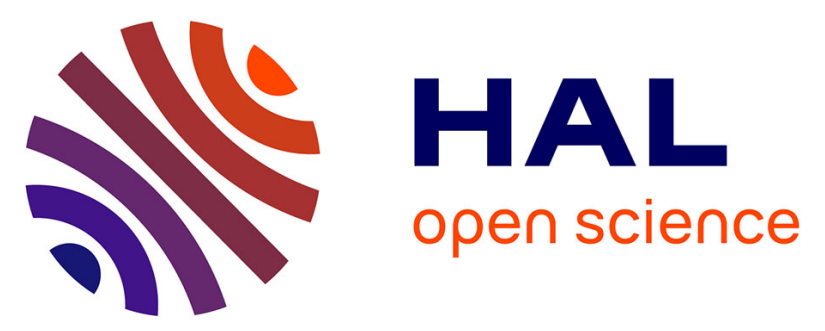

\title{
Progressive Folding and Adaptive Multivalent Recognition of Alkyl Amines and Amino Acids in p -Sulfonatocalix[4]arene Hosts: Solid-State and Solution Studies
}

Liya Dai, Wei-xu Feng, Shao-ping Zheng, Ji-jun Jiang, Dawei Wang, Arie van

Der Lee, Dan Dumitrescu, Mihail Barboiu

\section{To cite this version:}

Liya Dai, Wei-xu Feng, Shao-ping Zheng, Ji-jun Jiang, Dawei Wang, et al.. Progressive Folding and Adaptive Multivalent Recognition of Alkyl Amines and Amino Acids in p -Sulfonatocalix[4]arene Hosts: Solid-State and Solution Studies. ChemPlusChem, 2020, 85 (8), pp.1623 - 1631. 10.1002/cplu.202000232 . hal-03028969

\section{HAL Id: hal-03028969 https://hal.science/hal-03028969}

Submitted on 27 Nov 2020

HAL is a multi-disciplinary open access archive for the deposit and dissemination of scientific research documents, whether they are published or not. The documents may come from teaching and research institutions in France or abroad, or from public or private research centers.
L'archive ouverte pluridisciplinaire HAL, est destinée au dépôt et à la diffusion de documents scientifiques de niveau recherche, publiés ou non, émanant des établissements d'enseignement et de recherche français ou étrangers, des laboratoires publics ou privés. 


\title{
Progressive Folding and Adaptive Multivalent Recognition of Alkyl Amines and Amino Acids in p-Sulfonatocalix[4] arene Hosts: Solid-State and Solution Studies
}

\author{
Liya Dai, ${ }^{[a]}$ Wei-Xu Feng, ${ }^{[c]}$ Shao-Ping Zheng, ${ }^{[a]}$ Ji-Jun Jiang, ${ }^{[a]}$ Dawei Wang, ${ }^{[a]}$ \\ Arie van der Lee, ${ }^{[b]}$ Dan Dumitrescu, ${ }^{[d]}$ and Mihail Barboiu ${ }^{*[a, b]}$
}

\begin{abstract}
Calix[4]arenes have the ability to encapsulate biomimetic guests, offering interesting opportunities to explore their molecular recognition, very close to biological scenarios. In this study, $p$-sulfonatocalix[4]arene (C4 A) anions and hydrated alkali cations have been used for the in situ recognition of cationic $1, \omega$-diammonium-alkanes and 1, $\omega$-amino-acids of variable lengths. NMR spectroscopy illustrates that these systems are stable in aqueous solution and the interaction process involves several binding states or stabilized conformations within the C4 A anion, depending of the nature of the guest. DOSY
\end{abstract}

\section{Introduction}

The deciphering of the supramolecular binding events under confined conditions or pore environments is of paramount importance for understanding interactional mechanisms. ${ }^{[1]}$ Highly flexible molecules could in principle self-assemble with a variable probability under confined conditions, depending on its own and host structural behaviors. Precise structural characterization of such complex interactions is a necessary step towards the development of new methods of non-covalent modification for interaction and function modulation or for increasing the crystallization abilities of such non-crystalline molecules. ${ }^{[2,3]}$

Synthetic water soluble calixarenes, curcubiturils or foldamers enable the recognition of various molecules of bio-

[a] L. Dai, S.-P. Zheng, Dr. J.-J. Jiang, Dr. D. Wang, Dr. M. Barboiu

Lehn Institute of Functional Materials

School of Chemistry

Sun Yat-Sen University

Guangzhou 510275 (P. R. China)

[b] Dr. A. van der Lee, Dr. M. Barboiu

Institut Europeen des Membranes

Adaptive Supramolecular Nanosystems Group

University of Montpellier, ENSCM-CNRS

Place E. Bataillon CC047, 34095 Montpellier (France)

E-mail: mihail-dumitru.barboiu@umontpellier.fr

[c] Dr. W.-X. Feng

Department of Applied Chemistry

School of Science

Northwestern Polytechnical University

i'an, Shannxi 710129 (P. R. China)

[d] D. Dumitrescu

XRD2 beamline, Elettra - Sincrotrone Trieste S.C.p.A.

Strada Sta4tale 14 - km 163,5 in AREA Science Park

34149 Basovizza, Trieste (Italy)

Supporting information for this article is available on the WWW under https://doi.org/10.1002/cplu.202000232 experiments showed that monomeric $1: 1$ host-guest species are present, while the cation does not influence their selfassembly in solution. The folded conformations observed in the solid-state $\mathrm{X}$-ray single-crystal structures shed light on the constitutional adaptivity of flexible chains to environmental factors. Futhermore, a comprehensive screening of 30 single crystal structures helped to understand the in situ conformational fixation and accurate determination of the folded structures of the confined guest molecules, with a compression up to $40 \%$ compared with their linear conformations.

logical interest. ${ }^{[1-3]}$ The water soluble $p$-sulfonatocalix[4]arene, first reported by Shinkai et al. in $1984,{ }^{[4]}$ have been shown to have a variety of biomedical applications including antiviral or anti-thrombotic activities, conducted via enzyme or protein recognition processes. ${ }^{[5]}$ The binding of different hosts by $p$ sulfonatocalix[4]arene receptors is largely driven in water by an hydrophobic effect, assisted by secondary non-covalent electrostatic and hydrogen bonding interactions. The structural information available to date has been used for potential applications in generating single crystals of cytochrome $\mathrm{c}^{[3 \mathrm{a}]}$ or lysozyme, ${ }^{[3 b]}$ for which specific interactional mechanisms can be described from X-ray crystallographic studies. From these studies, we know that lysine protein sites adopt folded conformation of their alkyl chains buried on hydrophobic $p$ sulfonatocalix[4]arene cavity, enabling further formation of salt bridges between the ammonium and sulfonate substituents, favoring the displacement of water molecules initially located in the cavity. ${ }^{[3]}$

Encapsulation methods offer excellent reasons for a complete characterization of molecular compression and recognition of small molecules under confinement inside artificial $\mathrm{H}$ bonded capsules in aqueous solution. ${ }^{[6,7]}$ As in biological systems, the constitutional hydrophobic recognition of the alkyl chains is supplementary reinforced via strong interactions between the host-guest components. ${ }^{[8,9]}$ Of practical interest in such processes is to precisely determine the molecular conformations of the guest molecules themselves or their synergetic supramolecular interactions with the host molecules. ${ }^{[10]}$ If a crystal may be obtained in a solution containing a compound of interest, the compound is integrated into the cavity and if this is then analyzed by X-ray crystallography, the structure of the encapsulated compound can be elucidated. The reduced degrees of freedom of encapsulated guests can be limited by 
anchoring them to the crystalline host molecules/systems, allowing a reduced amount of disorder. ${ }^{[10,11]}$

The use of water-soluble p-sulfonatocalix[4]arene alkali metal cation salts leads to a remarkably diverse range of crystalline bilayers, capsules, spheres or nanotubes that can encapsulate small, biologically important molecules in water. ${ }^{[12]}$ Crystalline Calix[4]box architectures, self-assembled from $p$ sulfonatocalix[4]arene, C4 A anions and guanidinium cations have been used for encapsulation of flexible non-crystalline biogenic guests, very close to confined biological conditions. ${ }^{[10,11,13]}$ We know from these studies that folded conformations of the guest molecules under confinement, are dramatically different from that observed in bulk solution. The ability to encapsulate molecular guests within crystalline $p$ sulfonatocalix[4]arene, offers novel interesting options to explore their flexible conformations and a whole range of interactional algorithms under confined biomimetic conditions, close to those observed for active pockets of natural proteins or enzymes.

Herein, we take advantage of hydrophobic folding via recognition within $\mathrm{p}$-sulfonatocalix[4]arene of two series of $1, \omega$ diammonium-alkanes and 1, $\omega$-amino acids of variable lengths and possessing variable ammonium and carboxylic anchoring groups, as presented in the most cases of natural protein recognition studies (Scheme 1). The exact structures of the complexes and, more important for this study, the novel folded conformations adopted by the bound molecular guests are revealed by X-ray crystallography.

The crystallization of p-sulfonatocalix[4]arene is promoted in the presence of hydrated alkali cations. It relies on the formation of alternative layers of p-sulfonatocalix[4]arene anions and hydrated alkali cations / water molecules stabilized in a hydrogen-bonded network interacting on the upper-rim with the sulfonate moieties and presenting a variable relative spatial disposition within the crystal, depending on the nature of the alkali cation which strongly impacts on confined guest molecules recognition within crystals. The inclusion of alkali cations allows access to different binding geometries, changing the shape and size of the confined space for the particular recognition regimes. Stabilization of folded alkyl chains is not a common process and very few reports show evidence of constrained adaptive conformations, giving answers on how

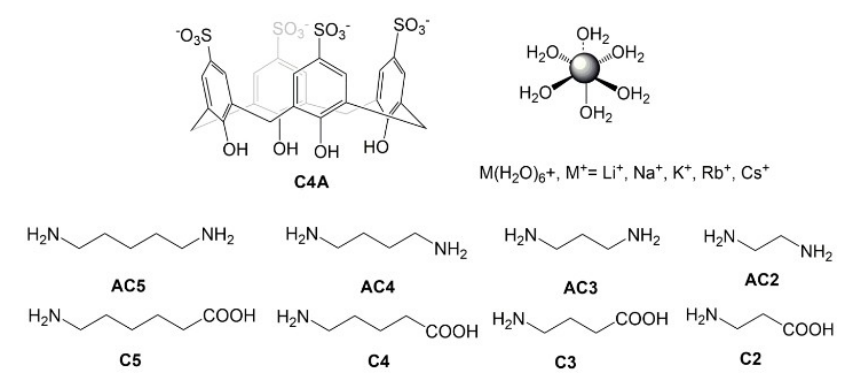

Scheme 1. p-sulfonatocalix[4]arene anion hosts C4 A, hydrated alkali cations $\mathrm{M}\left(\mathrm{H}_{2} \mathrm{O}\right)_{\mathrm{n}}^{+}\left(\mathrm{M}^{+}=\mathrm{Li}^{+}, \mathrm{Na}^{+}, \mathrm{K}^{+}, \mathrm{Rb}^{+}, \mathrm{Cs}^{+}\right)$and $1, \omega$-diammonium-alkanes $\mathrm{AC2}$ $\mathrm{AC5}$ and 1, $\omega$-amino acids $\mathrm{C2}$-C5 guests. alkane compression occurs and how this can impact further supplementary interactions under confined conditions. ${ }^{[14]}$

We have dedicated our studies to the confinement of two classes of guest molecules of biological interest with variable length and functional groups a) 1, $\omega$-diammonium-alkanes: 1,5diammonium-pentane, AC5 1,4-diammonium-butane, AC4 1,3diammonium-propane, AC3 and 1,2-diammonium-ethane, AC2 or b) 1, $\omega$-amino-acids: 6-aminohexanoic acid, C5 5-aminopentanoic acid, C4 4-aminobutyric acid, C3 and 2-aminoethanoic acid, C2. The host-matrixes has been readily obtained and crystallized in aqueous solutions of $p$-sulfonatocalix[4]arene anions C4 $\mathrm{A}$ and hydrated alkali cations $\mathrm{M}\left(\mathrm{H}_{2} \mathrm{O}\right)_{\mathrm{n}}{ }^{+}\left(\mathrm{M}^{+}=\mathrm{Li}^{+}\right.$, $\left.\mathrm{Na}^{+}, \mathrm{K}^{+}, \mathrm{Rb}^{+}, \mathrm{Cs}^{+}\right)$. At this point, several important questions are shedding light on: a) how important is the length of molecules squeezing progressively inside a fixed smaller chemical space and how does their folding contribute to the stabilization of the overall host-guest superstructure? b) How important is the nature of anchoring groups interacting with the sulfonate groups of p-sulfonatocalix[4]arene anions for the recognition? Systematic attempts to encapsulate biogenic protein side arms in confined space may generally furnish very interesting interactional details on their constitutional flexibility and interactional behaviors, inducing simultaneous changes of both capsule and host molecules. The conformation and compression could be precisely understood and confirmed by $X$-ray single-crystal structures in the solid state, as well as by NMR spectroscopy showing strong guest binding in aqueous solution.

\section{Results and Discussion}

${ }^{1} \mathrm{H}-\mathrm{NMR}$ Studies in Aqueous Solution. The host-guest interactions between the C4 A $p$-sulfonatocalix[4]arene host anions and protonated 1, $\omega$-diammonium-alkanes, AC5 to AC2 or 1, $\omega$ amino acids C5 to C2 cationic guests can be detected in aqueous solution. (Figure 1 and Figure 1S-7S in the Supporting Information). As a general trend, similar downfield shielding effects of $0.06-0.09 \mathrm{ppm}$ are detected for the singlet aromatic $\mathrm{H}_{\mathrm{A}}$ and methylene $\mathrm{H}_{B}$ protons of the C4 A platform adapting a cone conformation, when binding 1, $\omega$-diammonium-alkanes or $1, \omega$-amino-acids, indicating the alkali metal cations and cavity included guests are placed as connecting bridges between sulfonate moieties to compensate their overall charges. The formation of inclusion complexes of C4 A host anions with AC5 - AC2 or C5 - C2 protonated cationic guests in saline aqueous solutions of $\mathrm{NaCl}, \mathrm{KCl}, \mathrm{RbCl}, \mathrm{CsCl}$ can be clearly observed from the strong upfield shifts of the protons of the encapsulated guests (Figure 1) when compared with their spectral signals recorded in the absence of the $\mathrm{C} 4 \mathrm{~A}$. The signals corresponding to the protons are shielded: $\mathrm{H}_{1}(1.12$ and $1.27 \mathrm{ppm})$ for $\mathrm{AC} 4$ or (0.8 and $1.22 \mathrm{ppm}$ ) for $\mathrm{C} 4 ; \mathrm{H}_{2}$ (1.21 and $\left.1.29 \mathrm{ppm}\right)$ for AC4 or (0.6 and $0.8 \mathrm{ppm}$ ) for $\mathrm{C} 4$ and $\mathrm{H}_{3,4}(1.0$ and1.3 ppm) for $\mathrm{C} 4$ in the presence of $\mathrm{Na}^{+}$and $\mathrm{K}^{+}$cations. These broad proton signals are reminiscent of complex behaviors with the alkane chains fixed in two different conformations in fast dynamic exchange within the cavity. The prevalent interactions are $\mathrm{C}-\mathrm{H}-\pi$ between 


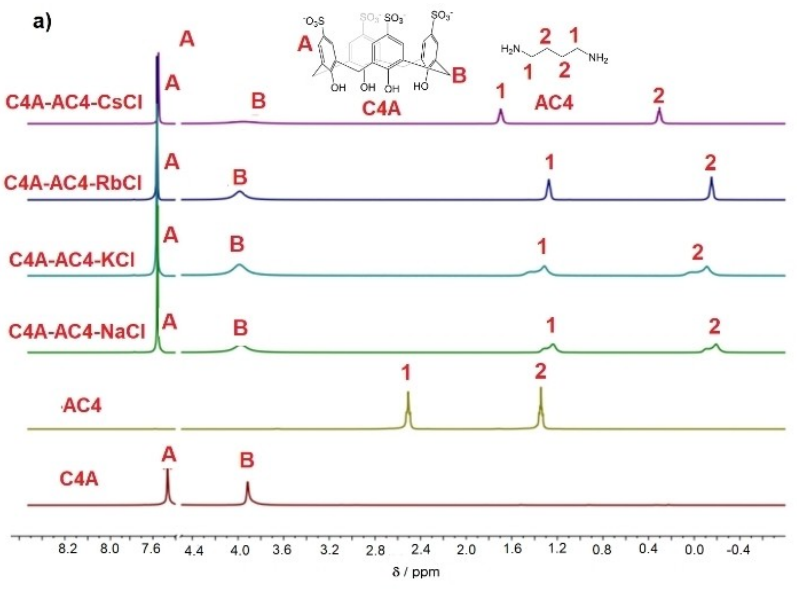

b)

Figure 1. ${ }^{1} \mathrm{H}-\mathrm{NMR}$ spectra at $25^{\circ} \mathrm{C}\left(400 \mathrm{MHz}, \mathrm{D}_{2} \mathrm{O}\right)$ of $\mathrm{C} 4 \mathrm{~A}$ host, $\mathrm{AC} 4, \mathrm{C} 4$ guests and p-sulfonatocalix[4]arene hosts: a) C4 A-AC4-MCl and b) C4 A-C4$\mathrm{MCl}$ prepared in saline solutions of $\mathrm{MCl}: \mathrm{LiCl} \mathrm{NaCl}, \mathrm{KCl}, \mathrm{RbCl}, \mathrm{CsCl}$. See Figures $1 \mathrm{~S}-7 \mathrm{~S}$ in the Supporting Information for NMR data of all other systems.

aliphatic protons of AC4 or C4 and aromatic phenyls of C4 A and the ion-pairing between the sulfonate groups of $\mathrm{C} 4 \mathrm{~A}$ and protonated ammonium groups of AC4 or C4. It is important to note that stronger upfield shielding is observed for the signals of the dicationic guest AC4 (Figure 1a) when compared with the mono-cationic amino-acid C4 (Figure 1a). It is supposing that AC4 molecule is doubly anchored via bis-ammonium groups and it is positioned on the deep part of the cavity, while mono-anchored C4 guest is situated more at the entry of the cavity. Moreover, differently to central $\mathrm{H}_{2}$ protons of AC4 which remain identical upon binding, the signals of central protons $\mathrm{H}_{3}$ and $\mathrm{H}_{4}$ of $\mathrm{C} 4$ present two sets of distinct signals, consistent their presence in different environments of $\mathrm{C} 4 \mathrm{~A}$, showing that host-guest interactions induce symmetric (AC4) or asymmetric (C4) confined placement of the respective guests upon guest recognition. The proton resonances are becoming sharp in the presence of $\mathrm{Rb}^{+}$and $\mathrm{Cs}^{+}$(AC4) or $\mathrm{K}^{+}$and $\mathrm{Rb}^{+}$(C4) alkali cations, reminiscent with a lower mobility of included guest molecules AC4 or C4 guests within the cavity of C4 A host, better stabilized in the presence of bigger cations bridging the sulfonate anions in solution. In addition, comparing the proton signals $\mathrm{H}_{1}(1.02 \mathrm{ppm})$ and $\mathrm{H}_{2}(0.71 \mathrm{ppm})$ for $\mathrm{Cs}^{+}$with the proton signals $\mathrm{H}_{1}(1.19 \mathrm{ppm})$ and $\mathrm{H}_{2} 1.29 \mathrm{ppm}$ for $\mathrm{Rb}^{+}$, they are both shifted upfield $\square$ OK? $\square$ by about 0.2 ppm in the presence of $\mathrm{Cs}^{+}$. This is consistent with that the guest AC4 changes the orientation toward the entry of host $\mathbf{C} 4 \mathbf{A}$ cavity in the presence of $\mathrm{Cs}^{+}$, while its binding is highly increased in the presence of $\mathrm{Rb}^{+}$cations, dimensionally more adapted and better stabilizing the rim of the $\mathrm{C} 4 \mathrm{~A}$ molecules than $\mathrm{Cs}^{+}$. Very interestingly the addition of different alkali cations (Figure $2 b$ ) do not induce any further changes in the recognition of monocationic C4 by C4 A anions and not affect much the equilibria in solution, as observed for AC4 guests in the presence of different alkali cations.

Furthermore, the DOSY spectroscopy (Figure 8S-14S) showed that monomeric 1:1, host : guest complexes are present in solution for the most of the studied systems. The calculated diffusion coefficients are presented in Table 1. The molecular volumes for C4 A, C4 A-AC4-RbCl and C4 A-C4-RbCl calculated from available crystal structure data reported in this paper, are $515.5 \AA^{3}, 730.4 \AA^{3}$ and $910.8 \AA^{3}$ respectively, Assuming that all molecules and self-assemblies are spherical, these volumes provide average hydrodynamic radii of $4.98 \AA$ for $\mathrm{C} 4 \mathrm{~A}$, $5.58 \AA$ for C4 A-AC4-RbCl and $6.02 \AA$ for C4 A-C4-RbCl, values, that predict the theoretical $D_{C 4 A-A C 4-R b C l} / D_{C 4 A}$ ratio of 0.89 and $D_{\text {C4A-C4-RbCl }} / D_{\text {C4A }}$ ratio of 0.82 . The experimental diffusion coefficients agree well with the theoretical ratios, indicating the presence of $1: 1$ complexes in solution and showing a small influence of the nature of alkali cations $\left(D_{\text {C4A-C4-KCI }} / D_{\text {C4A }}\right.$ ration of 0.72 ) on self-assembly behavior of monomeric $1: 1$ host : guest species in solution. The theoretical $D_{\text {C4A-AC4-RbCl }} / D_{\text {C4A }}=$ 0.56 provide an average hydrodynamic radius of $8.89 \AA$ and a total volume of $2941.5 \AA^{3}$ for C4 A-AC4-RbCl complex prepared at C4 A:AC4, 2:1, mol : mol ratio, which is consistent with an increase of the aggregation toward the self-assembly of polymolecular capsules, as previously reported by Atwood et al. ${ }^{[12]}$

On the basis of the NMR studies, one may conclude that alkyl strands of cationic 1, $\omega$-diammonium-alkanes, AC5 to AC2 or 1, $\omega$-amino-acids C5 to C2 are confined within p-sulfonatocalix[4]arene hosts, with a special emphasis for 1, $\omega$-diammoniumalkanes showing stronger stabilization when compared with the $1, \omega$-amino-acids, probably due to the double anchoring ammonium-sulfonate bridge-interactions on the rim of C4 A platform. This is also consistent with the multiple bent conformations of the alkyl chains under confinement observed

\begin{tabular}{|c|c|c|}
\hline Complex & $\begin{array}{l}\text { Diffusion coefficient, } \\
D\left[\mathrm{~m}^{2} \mathrm{~s}^{-1}\right]^{[a]}\end{array}$ & $\mathrm{D} / \mathrm{D}_{\mathrm{C} 4 \mathrm{~A}}$ \\
\hline C4 A-AC4-RbCl 1:1 & $2.54 \times 10^{-10}$ & 0.89 \\
\hline C4 A-AC4-RbCl 2:1 & $1.31 \times 10^{-10}$ & 0.56 \\
\hline $\mathrm{C} 4 \mathrm{~A}-\mathrm{C} 4-\mathrm{KCl}$ & $2.32 \times 10^{-10}$ & 0.72 \\
\hline $\mathrm{C} 4 \mathrm{~A}-\mathrm{C} 4-\mathrm{RbCl}$ & $2.44 \times 10^{-10}$ & 0.82 \\
\hline $\mathrm{C} 4 \mathrm{~A}-\mathrm{RbCl}$ & $2.95 \times 10^{-10}$ & - \\
\hline $\mathrm{AC4}$ & $5.76 \times 10^{-10}$ & - \\
\hline $\mathrm{C} 4$ & $4.93 \times 10^{-10}$ & - \\
\hline
\end{tabular}

[a] A diffusion constant value of $2.00 \times 0^{-9} \mathrm{~m}^{2} \mathrm{~s}^{-1}$ was assigned to the water signal. This value was used as reference for the calibration of the diffusion constant values assigned to the other species present in solution. 


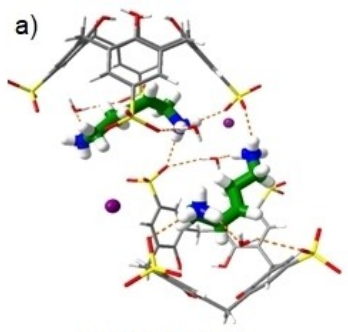

C4A-AC5-NaCl

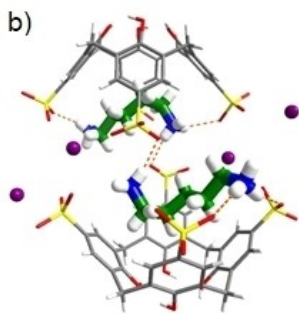

C4A-AC5-KCI c)

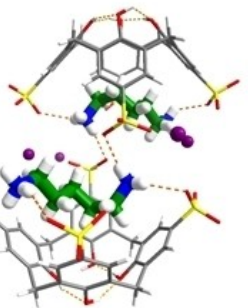

C4A-AC5-RbCl d)

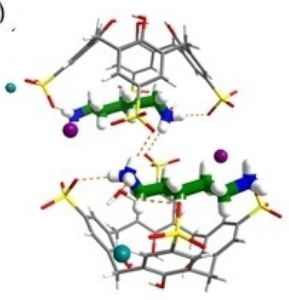

C4A-AC5-CsCl

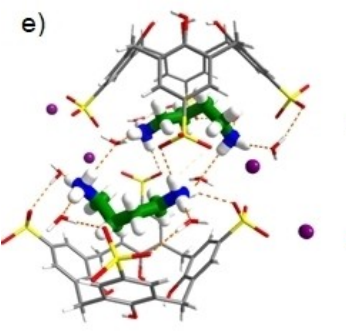

C4A-AC4-NaCl

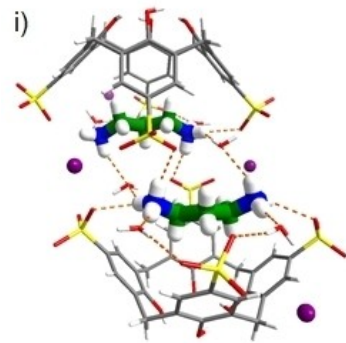

C4A-AC3-NaCl

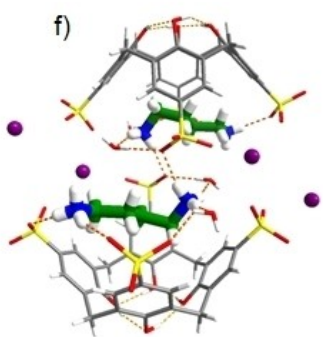

C4A-AC4-KCl

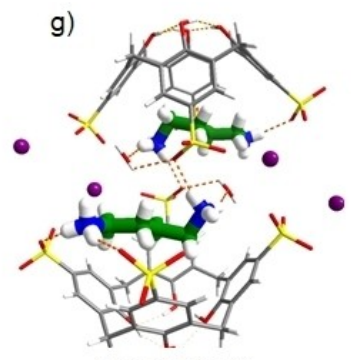

C4A-AC4-RbCl

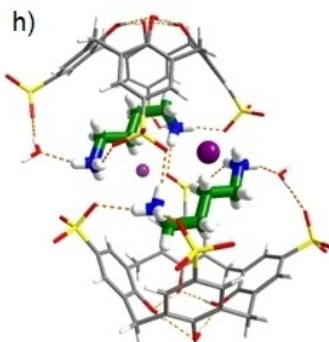

C4A-AC4-CsCl

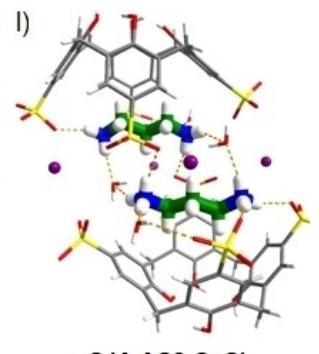

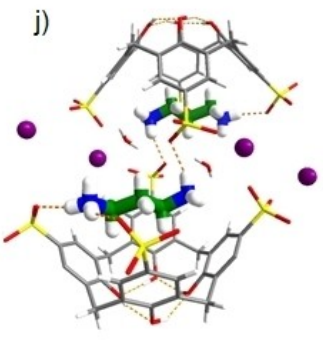

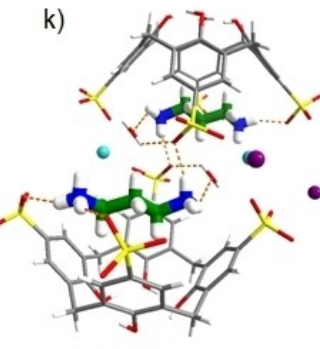

C4A-AC3-RbCl

C4A-AC3-CsCl

Figure 2. X-ray structures of a) C4 A-AC5-NaCl, b) C4 A-AC5-KCl, c) C4 A-AC5-RbCl, d) C4 A-AC5-CsCl, e) C4 A-AC4-NaCl, f) C4 A-AC4-KCl, g) C4 A-AC4-RbCl, h) C4 A-AC4-CsCl, i) C4 A-AC3- $\mathrm{NaCl}$, j) C4 A-AC3-KCl, k) C4 A-AC3-RbCl, I) C4 A-AC3-CsCl: Side view of the inclusion complexes and of the H-bonded matrices formed by $p$-sulfonatocalix[4]arene anion $\mathrm{C} 4 \mathrm{~A}$, hydrated alkali cations $\mathrm{M}\left(\mathrm{H}_{2} \mathrm{O}\right)_{n}{ }^{+}\left(\mathrm{M}^{+}=\mathrm{Li}^{+}, \mathrm{Na}^{+}, \mathrm{K}^{+}, \mathrm{Rb}^{+}, \mathrm{Cs}^{+}\right)$cations and the 1, $\omega$-diammonium-alkanes $\mathrm{AC2}$ AC5 guests.

in the X-ray single-crystal structures presented below. The broad proton signals are reminiscent of important dynamic behaviors of alkane chains during the ion-pairing process in the presence of smaller $\mathrm{Na}^{+}$or $\mathrm{K}^{+}$alkali cations. Oppositely they became sharper in the presence of bigger $\mathrm{Rb}^{+}$or $\mathrm{Cs}^{+}$cations, bringing important conformational stabilization of the interior chemical space, due to their ability to bridge the upper rim sulfonate moieties of C4 A platform. DOSY NMR experiments indicate the presence of $1: 1$ complexes in solution, with practically no influence of the nature of various alkali cations. Higher, more complex aggregates are formed in solution when an excess of C4 A (2:1 mol: $\mathrm{mol})$ is used in solution.

$\mathrm{X}$-ray single crystal structures. The recognition of guests observed in solution is supported by the X-ray single-crystal structures of C4 A host anions and of AC5 - AC2 or C5 - C2 protonated guests (Table S1-S5), ${ }^{[15]}$ obtained by slow evaporation of aqueous saline solutions ( $\mathrm{MCl}$ : $\mathrm{LiCl} \mathrm{NaCl}, \mathrm{KCl}, \mathrm{RbCl}, \mathrm{CsCl}$ ). They are resulting from the self-assembly of $\mathrm{C} 4 \mathrm{~A}$ anions, AC5 $\mathrm{AC2}$ or $\mathrm{C5}-\mathrm{C} 2$ guests and hydrated $\mathrm{Li}^{+}, \mathrm{Na}^{+}, \mathrm{K}^{+}, \mathrm{Rb}^{+}, \mathrm{Cs}^{+}$alkali cations and additional water molecules (Figure 2, 3). The guests penetrate and interact with C4 A cavity positioning their ammonium or carboxyl/water terminal moieties on the close proximity of the sulfonate groups, to form anchoring $\mathrm{H}$-bonds on the rim of the C4 A host molecules. The hydrogen bonding is reinforced by bridging water molecules, playing an important role in filling the interstices of the network.

In the C4 A-AC5-LiCl (Figure 15S), C4 A-AC5-NaCl (Figure 2a), C4 A-AC5-KCl, (Figure 2b) C4 A-AC5-RbCl (Figure 2c) and $\mathrm{C} 4 \mathrm{~A}-\mathrm{AC5}-\mathrm{CsCl}$ (Figure 2d) two protonated 1,5-Diammoniumpentane, AC5 guests are confined in the inner space between two C4 A anions, spatially disposed in a slightly slipped arrangement in parallel organic layers. They are stabilized with alternating inorganic lamellar phases of four hydrated $\mathrm{Li}^{+}, \mathrm{Na}^{+}, \mathrm{K}^{+}, \mathrm{Rb}^{+}$or $\mathrm{Cs}^{+} / \mathrm{Na}^{+}$cations and water molecules, bridging the sulfonate groups of $\mathrm{C} 4 \mathrm{~A}$, respectively. In all cases, the molecules of AC5 are doubly anchored via hydrogen bonding of one ammonium group between two sulfonate moieties $\left(\mathrm{d}_{\mathrm{N} \ldots \mathrm{O}}=2.03-2.05 \AA\right)$ and of the second ammonium group $\mathrm{H}$-bonded to bridging water molecules $\left(\mathrm{d}_{\mathrm{N} \ldots \mathrm{O}}=1.99 \AA\right)$ positioned between the opposite sulfonate moieties of the $\mathbf{C} 4 \mathbf{A}$.

Additional hydrogen bonding/bridging interactions take place between the ammonium groups of the AC5 guests and sulfonate groups of vicinal C4 A anions. In these structures the AC5 guest molecules are longer to fit the constraints of the recognition environment. The confined molecules of AC5 
guests present folded conformations adapting and asymmetrically filling the space of the C4 A platform. The conformers of AC5 present slightly different geometries depending on the nature of alkali cation. They have two gauche conformations between the C1-C2 and C2-C3 for C4 A-AC5-LiCl, C4 A-AC5$\mathrm{NaCl}, \mathrm{C} 4 \mathrm{~A}-\mathrm{AC5}-\mathrm{KCl}$ or $\mathrm{C} 4 \mathrm{~A}-\mathrm{AC5}-\mathrm{RbCl}$ and one gauche conformation between $\mathrm{C} 1-\mathrm{C} 2$ for $\mathrm{C} 4 \mathrm{~A}-\mathrm{AC} 5-\mathrm{CsCl}$, respectively. They are unsymmetrically positioned at one end of the alkane chains, presenting close hydrophobic $\mathrm{C}-\mathrm{H}$ (alkyl)/ $\pi$ aromatic centroids (calix[4]arene) contacts of $2.50-2.90 \AA$ and floating in the aromatic cavity of $\mathrm{C} 4 \mathrm{~A}$. The $\mathrm{N}_{1}-\mathrm{N}_{5}$ distances between the ammonium groups of the confined AC5 guests in C4 A-AC5$\mathrm{LiCl}, \mathrm{C} 4 \mathrm{~A}-\mathrm{AC} 5-\mathrm{NaCl}, \mathrm{C} 4 \mathrm{~A}-\mathrm{AC} 5-\mathrm{KCl}$ or C4 A-AC5-RbCl, are around $5.62-5.83 \AA$, corresponding to a $23.98-20.40 \%$ compression of the extended linear length of AC5, while conformer AC5 immobilized in C4 A-AC5-CsCl, is more elongated at $6.71 \AA$, with a compression of $9.26 \%$.

In the C4 A-AC4- $\mathrm{NaCl}$ (Figure 2e), C4 A-AC4-KCl (Figure 2f), C4 A-AC4-RbCl (Figure 2g) and C4 A-AC4-CsCl (Figure. $2 \mathrm{~h}$ ) two protonated 1,4-Diammonium-butane, AC4 guests are confined within the inner space between two C4 A anions spatially disposed in a slipping paralleled near face to face arrangement. Four $\mathrm{Na}^{+}, \mathrm{K}^{+}, \mathrm{Rb}^{+}$or $\mathrm{Cs}^{+}$cations with eight bridging water molecules constitute the inorganic layer, stabilizing parallel C4 A anion layers. The guest molecules are anchored via hydrogen bonding of bridging ammonium groups between two sulfonates groups $\left(\mathrm{d}_{\mathrm{N} \ldots \mathrm{O}}=1.96-1.98 \AA\right)$ and via two water molecules bridging the other two opposite sulfonate groups $\left(d_{N \cdots O}=2.05-2.37 \AA\right)$. The stability of the network is reinforced via six or eight anchoring $\mathrm{H}$-bonds $\left(\mathrm{d}_{\mathrm{N} . \mathrm{O}}=1.95-2.33 \AA\right.$ ) between the ammonium moieties of AC4 guests and the sulfonate moieties of the vicinal C4 A host anions. The guests AC4 get compressed and present folded asymmetrical conformations inside the C4 A cavity, with one gauche C1-C2 conformation positioned at one end of the alkane chains. This buried part of the chains is in hydrophobic $\mathrm{C}-\mathrm{H}$ (alkyl) / $\pi$ aromatic centroids (calix[4]arene) contacts of $2.90-3.00 \AA$ and floating in the aromatic cavity of $\mathrm{C} 4 \mathrm{~A}$ The $\mathrm{N}_{1}-\mathrm{N}_{4}$ distances between the ammonium groups of confined $\mathrm{AC} 4$ guests in $\mathrm{C} 4 \mathrm{~A}-\mathrm{AC} 4-\mathrm{NaCl}$, C4 A-AC4-KCl, C4 A-AC4-RbCl or C4- ${ }^{-} \mathrm{AC4}-\mathrm{CsCl}$ are 5.09 $-5.44 \AA$, corresponding to a $10.20-17.05 \%$ compression of the extended linear length of AC4.

In the C4 A-AC3-NaCl (Figure 2i), C4 A-AC3-KCl (Figure 2j), C4 A-AC3-RbCl (Figure 2k) and C4 A-AC3-CsCl (Figure 2l) two 1,3-Diammonium-propane, AC3 protonated guests are perfectly fitting to the distance between the sulfonate groups in the inner space of the C4 A anions, spatially disposed in a slipping paralleled near face to face arrangement. Four $\mathrm{Na}^{+}, \mathrm{K}^{+}, \mathrm{Rb}^{+}$or $\mathrm{Cs}^{+}$cations with bridging water molecules are stabilizing the inorganic layer, parallel to the layer of C4 A anions. The molecular chains of AC3 adopting a classical 'zig-zag' linear conformation, are symmetrically anchored via multiple hydrogen bonding $\left(\mathrm{d}_{\mathrm{N} \ldots \mathrm{O}}=1.91-2.10 \AA\right)$ of ammonium groups bridging the two sulfonates groups, on the opposite sides of C4 A. Remarkably any water molecule is present to reinforce this recognition motif. The $\mathrm{N}_{1}-\mathrm{N}_{3}$ distances of confined $A C 3$ guest in C4 A-AC3-NaCl, C4 A-AC3-KCl, C4 A-AC3-RbCl or C4 A-AC3-
CsCl are $4.82-4.90 \AA$, corresponding to practically no-compression, $1.44-3.27 \%$ of the extended linear length of the $\mathrm{AC} 3$ guest. More remarkable, two confined molecules of AC3 guest with linear non-folded conformations are filling the space within C4 A platforms, showing practically no hydrophobic $\mathrm{C}-\mathrm{H}$ (alkyl) / $\pi$ aromatic (calix[4]arene) contacts which are greater than $3.00 \AA$ with the C4 A cavity.

When shorter deprotonated AC2 1,2-Diammoniumethane guests are used, interestingly they are not included in the aromatic cavity of C4 A. The single crystal structures of C4 AAC2-LiCl (Figure 16Sa) and C4 A-AC2-NaCl (Figure 16Sb), consists of layered structures with C4 A anions, confining three water molecules within their cavity as previously observed ${ }^{[16]}$ and having lower hydroxyl rims connected by four $\mathrm{Li}^{+}$cations or upper rim of sulfonate moieties connected by four hydrated $\mathrm{Na}^{+}$cations, respectively. The protonated 1,2-Diammoniumethane, AC2 guest are probably too hydrophilic to fill the inner space of the C4 A anions and they are disposed together with hydrated $\mathrm{Li}^{+}$and $\mathrm{Na}^{+}$cations and bridging water molecules outside the cavity of the C4 A anion. The AC2 guests have gauche conformations of the C1-C2 alkane chain and they are $\mathrm{H}$-bonded via ammonium groups to sulfonate groups of the C4 A anion.

In the C4 A-C5-LiCl (Figure 3a) and C4 A-C5-KCl (Figure 3b) two confined guests protonated 6-aminohexanoate, C5 guest molecules are filling in the inner space between two $\mathrm{C}^{4-}$ anion hosts, spatially disposed in a slipping parallel arrangement. The guest molecules C5 are anchored via hydrogen bonding of bridging ammonium groups between two sulfonates groups of C4 A $\left(d_{N \ldots O}=2.16-2.3 \AA\right)$. The hydrogen bonding network is reinforced by four hydrated $\mathrm{Li}^{+}$or $\mathrm{K}^{+}$cations and four bridging water molecules which are $\mathrm{H}$-bonded to carboxyl groups of $\mathrm{C5}$ $\left(\mathrm{d}_{0 . . .0}=2.02-2.17 \AA\right)$, playing a crucial role in the stabilization of the guests inside the cavity of the $\mathrm{C4}^{4-}$ anions network. In addition, each carboxyl groups of one guest is $\mathrm{H}$-bonded $\left(\mathrm{d}_{\mathrm{N} \ldots \mathrm{O}}=1.89 \AA\right)$ to the ammonium moiety of a vicinal C5 pair guest generating dimers of $\mathbf{C 5}_{2}$ within the capsule. The molecules of $\mathrm{C} 5$ are presenting one gauche conformation (C1-C2) at the 'carboxylate' end of the alkane chain showing close hydrophobic $\mathrm{C}-\mathrm{H}$ (alkyl) / $\pi$ (calix[4]arene) contacts of 2.70-2.90 $\AA$ with the aromatic cavity of C4 A. The $\mathrm{N}_{1}-\mathrm{O}_{6}$ distances between the ammonium and carboxylate groups of confined C5 guest in C4 A-C5- LiCl and C4 A-C5-KCl, are strongly dependent on the nature of the cation $6.61 \AA\left(\mathrm{Li}^{+}\right)$and $5.66 \AA\left(\mathrm{K}^{+}\right)$and directly influenced by the anchoring position of the carboxylate group within the network. They correspond to $11.53 \%$ and $24.03 \%$ compression of the extended linear length of C5. In theC4 A-C4-NaCl (Figure 3C), C4 A-C4-KCl (Figure 3d) C4 A-C4-RbCl (Figure 3e) C4 A-C4-CsCl (Figure 3f) two protonated 5-aminopentanoic acid, C4 guests are confined within the confined inner cavity defined between two C4 A anions, variably disposed in a slipping parallel to face to face arrangements depending on the nature of hydrated cations. The hydrated $\mathrm{Na}^{+}, \mathrm{K}^{+}, \mathrm{Rb}^{+}$or $\mathrm{Cs}^{+} / \mathrm{Na}^{+}$cations forming inorganic layers are compensating the negative charge of $\mathbf{C 4} \mathrm{A}$ and are subsequently coordinating the carboxylates of $\mathrm{C} 4$ guests and 
a)
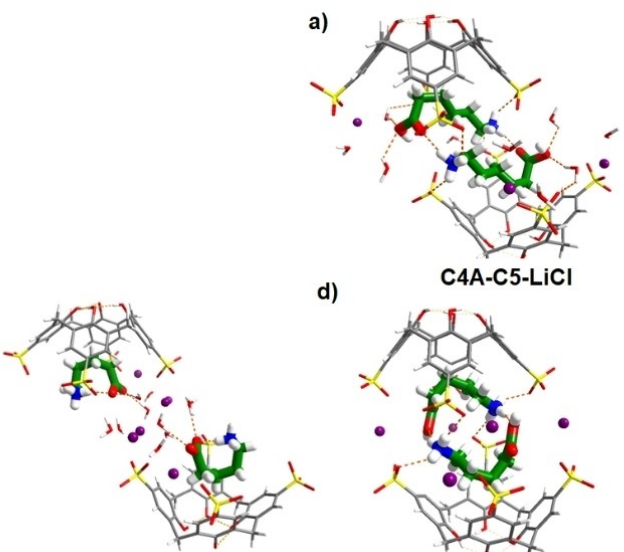

C4A-C4-NaCl

g)

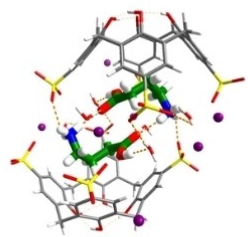

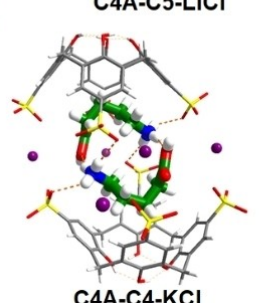

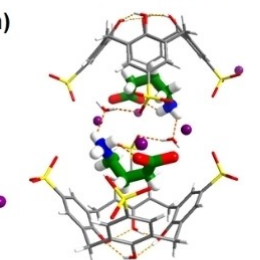

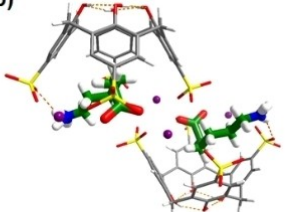

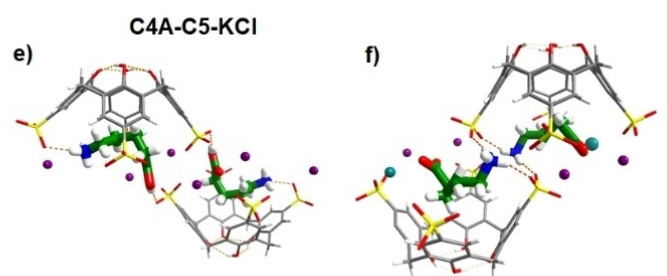

C4A-C4-RbCl

i)

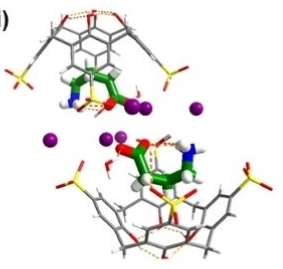

$\mathrm{C} 4 \mathrm{~A}-\mathrm{C} 3-\mathrm{KCl}$

C4A-C4-CsCl

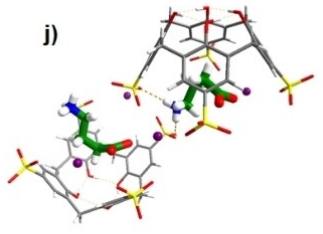

k)

C4A-C3-LiCl

C4A-C3-NaCl

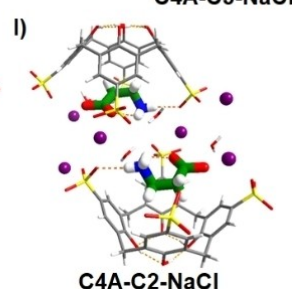

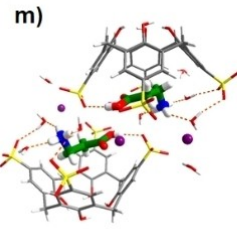

C4A-C2-KCI

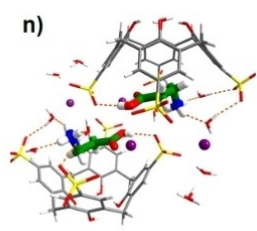

$\mathrm{C} 4 \mathrm{~A}-\mathrm{C} 2-\mathrm{RbCl}$
C4A-C3-CsCI

o)

Figure 3. X-ray structures of a) C4 A-C5-LiCl, b) C4 A-C5-KCl, c) C4 A-C4-RbCl, d) C4 A-C4-KCl, e) C4 A-C4-RbCl, f) C4 A-C4-CsCl, g) C4 A-C3-LiCl, h) C4 A-C3$\mathrm{NaCl}$, i) C4 A-C3-KCl, j) C4 A-C3-CsCl, k) C4 A-C2-LiCl, I) C4 A-C2-NaCl, m) C4 A-C2-KCl n) C4 A-C2-RbCl, o) C4 A-C2-CsCl: Side view of the inclusion complexes side view and of the $\mathrm{H}$-bonded matrices formed by $p$-sulfonatocalix $[4]$ arene anion $\mathrm{C} 4 \mathrm{~A}$, hydrated alkali cations $\mathrm{M}\left(\mathrm{H}_{2} \mathrm{O}\right)_{\mathrm{n}}{ }^{+}\left(\mathrm{M}^{+}=\mathrm{Li}^{+}, \mathrm{Na}^{+}, \mathrm{K}^{+}, \mathrm{Rb}^{+}\right.$, $\mathrm{Cs}^{+}$) cations and the 1, 1 -diammonium-alkanes C5-C2 guests.

hydrogen bonding via bridging water molecules to the sulfonate groups of C4 A.

The hydrogen bonding network is reinforced by anchoring $\mathrm{H}$-bonds between the ammonium moieties of $\mathrm{C} 4$ and sulfonate groups $\left(\mathrm{d}_{\mathrm{N} \ldots \mathrm{O}}=2.18\right.$ and $\left.2.07 \AA\right)$ or via bridging water molecules to the sulfonate groups of different C4 A platforms. Depending on the nature of the cation and of the positioning of the anchoring points in the network, the $\mathrm{C} 4$ guest is differently packed within the capsule. In the $\mathrm{C} 4 \mathrm{~A}-\mathrm{C} 4-\mathrm{NaCl}$ (Figure $3 \mathrm{c}$ ) the C4 guest adopts an asymmetrical highly compressed conformation, with three gauche conformations among C1-C2, C2-C3, C3C4 positioned all the length of the alkyl chain so that a strong hydrogen bonding $\left(d_{N \ldots O}=2.07 \AA\right)$ is intramolecularly established between the ammonium and carboxyl groups of the folding $\mathbf{C 4}$ guest. The $\mathbf{C 4}$ guests in $\mathrm{C4} \mathrm{A}-\mathrm{C} 4-\mathrm{KCl}$ (Figure $3 \mathrm{~d}$ ) have two gauche conformations between $\mathrm{C} 2-\mathrm{C} 3$ and $\mathrm{C} 3-\mathrm{C} 4$ unsymmetrically and contiguously positioned at the end of ammonium group of the alkane chains, while in $\mathrm{C} 4 \mathrm{~A}-\mathrm{C} 4-\mathrm{RbCl}$ (Figure 3e) C4 A-C4-CsCl (Figure 3f) the C4 guests became more relaxed having one gauche conformations of $\mathrm{C} 3-\mathrm{C} 4$ unsymmetrically positioned at the neighboring end of carboxyl group of the alkyl chain. All the structures show close hydrophobic
$\mathrm{C}-\mathrm{H}($ alkyl)/ $/ \pi$ (calix[4]arene) contacts of contacts of $2.50-2.70 \AA$ of folded C4 guests with the aromatic cavity of C4 A. The $\mathrm{N}_{1}-\mathrm{O}_{5}$ distances between the ammonium and carboxylate groups of confined C4 guest in C4 A-C4-NaCl, C4 A-C4-KCl C4 A-C4-RbCl C4 A-C4-CsCl are strongly dependent on the nature of the cation and the relative intramolecular compression of the folded molecule of C4 directly influenced by the anchoring position of the carboxylate and ammonium group within the network and corresponding to strong $43.06 \%\left(\mathrm{Na}^{+}\right)$to $17.87 \%$ $\left(\mathrm{Cs}^{+}\right)$compression of the extended linear length of $\mathrm{C} 4$.

In the C4 A-C3-LiCl (Figure 3g), C4 A-C3-NaCl (Figure 3h), C4 A-C3-KCl (Figure 3i), C4 A-C3-CsCl (Figure 3j), two confined protonated $\gamma$-aminobutyric acid $\mathrm{C} 3$ guests are encapsulated in the inner space between two $\mathrm{C4}^{4-}$ anions, variably disposed in a slipping parallel to face to face arrangements. This network is reinforced by hydrogen bonding of six hydrated $\mathrm{Li}^{+}, \mathrm{Na}^{+} \mathrm{K}^{+}$or four $\mathrm{Cs}^{+}$cations and six bridging water molecules, playing a crucial role in stabilizing the network. Both guest molecules of C3 are anchored via hydrogen bonding of ammonium groups forming two anchoring $\mathrm{H}$-bonds with sulfonates $\left(\mathrm{d}_{\mathrm{N} . \mathrm{O}}=2.28 \AA\right.$ ) and two $\mathrm{H}$-bonds with bridging water molecule connecting to sulfonate $\left(\mathrm{d}_{\mathrm{N} \ldots \mathrm{O}}=2.18 \AA\right)$ and carboxyl groups $\left(\mathrm{d}_{\mathrm{N} \ldots \mathrm{O}}=2.07 \AA\right)$ 
forming encapsulated dimers. In addition, the carboxy groups is anchored via hydrogen bonding to bridging water molecule in the inorganic cationic layer of the network $\left(\mathrm{d}_{\mathrm{N} \ldots \mathrm{O}}=1.78 \AA\right.$ ). The molecules of $\mathrm{C} 3$ are highly compressed inside the cavity, presenting two all-gauche conformations $\mathrm{C} 1-\mathrm{C} 2$ and $\mathrm{C} 2-\mathrm{C} 3$ and in the case of $\mathrm{C} 4 \mathrm{~A}-\mathrm{C} 3-\mathrm{NaCl}$ and $\mathrm{C} 4 \mathrm{~A}-\mathrm{C} 3-\mathrm{KCl}$ an intramolecular hydrogen bond $\left(\mathrm{d}_{\mathrm{N} \ldots \mathrm{O}}=2.28-2.36 \AA\right.$ ) between ammonium and carboxyl groups is stabilizing the highly folded conformation of the guests. In the case of $\mathrm{C} 4 \mathrm{~A}-\mathrm{C} 3-\mathrm{CsCl}$ one gauche conformation of $\mathrm{C} 1-\mathrm{C} 2$ is positioned at the neighboring end of carboxyl group coordinated to hydrated $\mathrm{Cs}^{+}$cations, which are subsequently connected to sulfonate groups via hydrogen bonding to the C4 A platforms. The encapsulated C3 guests are stabilized via hydrophobic $\mathrm{C}-\mathrm{H}$ (alkane chains) / $\pi$ (calix[4] arene) short contact of contacts of 2.50-2.70 $\AA$, which play important role in confining guests inside the C4 A cavity. The $\mathrm{N}_{1}-\mathrm{O}_{3}$ distances between the ammonium and carboxylate groups of confined C3 guest in C4 A-C3-LiCl and C4 A-C3-KCl, are strongly dependent on the nature of the cation, directly determining the anchoring positions within the network or internal hydrogen bonding and presenting S-type gauchegauche $3.83 \AA\left(\mathrm{Li}^{+}\right)$or gauche- $4.28 \AA\left(\mathrm{Cs}^{+}\right)$conformers or highly compressed gauche-gauche $3.30 \AA\left(\mathrm{Na}^{+}\right)$or $3.23 \AA\left(\mathrm{K}^{+}\right)$conformers, corresponding to $13.51 \%$ to $34.81 \%$ compression of the extended linear length of C3.

In the C4 A-C2-LiCl (Figure 3k), C4 A-C2-NaCl (Figure 3l), C4 A-C2-KCl (Figure 3m), C4 A-C2-RbCl (Figure 3n), C4 A-C2$\mathrm{CsCl}$ (Figure 3o), on contrary to their more hydrophilic diprotonated 1,2-Diammoniumethane AC2, two protonated 2-aminoethanoic acid, C2 guests are confined within the inner cavity consisting of two C4 A platforms disposed in a slipping parallel to face to face arrangements. Several hydrated $\mathrm{Li}^{+}, \mathrm{Na}^{+}, \mathrm{K}^{+}, \mathrm{Rb}^{+}$ or $\mathrm{Cs}^{+}$cations and bridging water molecules play a crucial role in stabilization of the network. The molecules of C2 are anchored via hydrogen bonding of ammonium groups to sulfonates $\left(\mathrm{d}_{\mathrm{N} \ldots \mathrm{O}}=2.09 \AA\right)$ or via two bridging water molecules further connecting to sulfonates $\left(d_{N \ldots o}=1.97-2.05 \AA\right.$ ). In addition, the carboxyl groups are $\mathrm{H}$-bonded $\left(\mathrm{d}_{0 . \ldots \mathrm{O}}=1.93 \AA\right)$ to sulfonate moieties of C4 A platform. The intramolecular hydrogen bonding $\left(\mathrm{d}_{\mathrm{N} \ldots \mathrm{O}}=2.28 \AA\right)$ between ammonium group and carboxyl group contributes to the stabilization of the folded conformation of the guests C2 under confinement. The guests of C2 present one gauche conformations of C1-C2 of the alkane chains and they are not interacting via hydrophobic $\mathrm{C}-\mathrm{H}$ (alkane chains)/ $\pi$ (calix[4]arene) inside the $\mathrm{C} 4 \mathrm{~A}$ cavity. The $\mathrm{N}_{1}-\mathrm{O}_{3}$ distances between the ammonium and carboxylate groups of confined guests C2 are 3.02-3.15 and are related to the gauche conformation of the confined $\mathrm{C} 2$ guest within the cavity of C4 A and corresponding to $15.00 \%$ compression of the extended linear length of $\mathbf{C} 2$.

\section{Conclusion}

Molecular recognition of the flexible biogenic molecules has long intrigued chemists on account of their important role in regulating protein structures, functions, and aggregation be- haviours. $^{1-3}$ Simple molecular receptors can be used to recognize these systems with strained geometries and variable adaptive behaviours.

In this paper we highlighted that the 1, $\omega$-diammoniumalkanes or the $1, \omega$-amino acids chains may be successfully constrained/anchored inside the p-sulfonatocalix[4]arene. Detailed comprehensive crystallographic characterization with more than 30 single crystal structures are supporting a complete survey on different structural behaviours that can affect the recognition events.

Variable relative spatial disposition of the p-sulfonatocalix[4] arene C4 A anionic platforms within the crystal strongly depend on the nature of alkali hydrated counter cations and induce a different dimensional disposition of the sulfonate and of the alkali cation anchoring points used for the guest binding. The guest molecules are double $\mathrm{H}$-bonded via ammonium and carboxylate groups to the sulfonates and present a bentgeometry with one/two gauche conformations, unsymmetrically positioned in the terminal part of the alkane chain, buried within the hydrophobic part of p-sulfonatocalix[4]arene. The 1, $\omega$-diammonium-alkanes are anchored via double ammoniumsulfonate bridges while $1, \omega$-amino acids are connected via combined ammonium-sulfonate / carboxylate water/alkali cation interactions on the rim of C4 A platform. The nature of the hydrated metal cations it is highly important in the positioning of the guest and determines its conformation upon recognition. In the case of 1, $\omega$-diammonium-alkanes, the compression of longer molecules AC5 and AC4 follows the sequence: $\mathrm{Na}^{+}>\mathrm{K}^{+}$ $>\mathrm{Rb}^{+}>\mathrm{Cs}^{+}$(Table 3), with a higher compression of the guests observed for $\mathrm{Na}^{+}$cations, which is almost twice stronger than for $\mathrm{Cs}^{+}$cations. This is related to their position closer to the sulfonate moieties on the upper-rim of p-sulfonatocalix[4]arene, that better stabilize the rigid cone conformation for the recognition space of the host. The $\mathrm{Na}^{+}$cations are probably fulfilling the best compromise to compensate the charge/ $\mathrm{H}$ bond interactions within the network. The same effect has been observed for 1, $\omega$-amino acid guests for which the $\mathrm{Na}^{+}$cations are inducing a maximum folding with three or two gauche conformations, so that a strong hydrogen bonding is intramolecularly established between the ammonium and carboxyl groups of the folding C4 and C3 guests (Table 2).

Another key function of $p$-sulfonatocalix[4]arene as receptor in water, is the burial of a part of the molecule of the guest within a confining space offered by its concave cavity and it is directly relating to progressive bent conformations of the alkyl chains under confinement. Regardless, it appears that the main driving forces for recognition are the steric compatibility of the alkyl chains fitting the cavity, optimal for the uncompressed 1,3-Diammonium-propane AC3 guests, as well as intramolecular electrostatic/ hydrogen bonding stabilization of U-shape guests of $\gamma$-aminobutyric acid C3 guests. The longer ones adopt folded conformations at different levels of compression depending on their molecular dimensional behaviours that can be detected in solution and are sufficiently kinetic stable under the confined conditions in the solid state, to allow a conventional structure determination by X-ray diffraction. 


\begin{tabular}{|c|c|c|c|c|c|}
\hline Guest & $\mathrm{LiCl}$ & $\mathrm{NaCl}$ & $\mathrm{KCl}$ & $\mathrm{RbCl}$ & $\mathrm{CsCl}$ \\
\hline AC5 & & & & & \\
\hline $\mathrm{d}_{\mathrm{N}-\mathrm{N}}[\AA]^{[\mathrm{a}]}$ & 5.6272 & 5.8231 & 5.8920 & 5.8348 & 6.7164 \\
\hline Compression $^{[b]}$ & $23.98 \%$ & $21.33 \%$ & $20.40 \%$ & $21.17 \%$ & $9.26 \%$ \\
\hline AC4 & - & & & & \\
\hline $\mathrm{d}_{\mathrm{N}-\mathrm{N}}[\AA]$ & - & 5.0971 & 5.5127 & 5.5166 & 5.4447 \\
\hline Compression & - & $17.05 \%$ & $10.28 \%$ & $10.22 \%$ & $11.39 \%$ \\
\hline$A C 3$ & - & & & & \\
\hline $\left.\mathrm{d}_{\mathrm{N}-\mathrm{N}}[\AA]\right]$ & - & 4.8239 & 4.9163 & 4.9061 & 4.8420 \\
\hline Compression & - & $3.27 \%$ & $1.44 \%$ & $1.62 \%$ & $2.91 \%$ \\
\hline $\mathrm{AC2}$ & & & - & - & - \\
\hline $\left.\mathrm{d}_{\mathrm{N}-\mathrm{N}}[\AA]\right]$ & 3.1339 & 3.1177 & - & - & - \\
\hline Compression & $13.62 \%$ & $14.07 \%$ & - & - & - \\
\hline
\end{tabular}

[a] $\mathrm{d}_{\mathrm{N}-\mathrm{N}}$ distance between the $\mathrm{N}$ atoms of the ammonium groups of encapsulated conformers, [b] Compression rate relative to the extended linear conformer. Compression $\%=L_{\text {linear }}-L_{\text {conformer }} / L_{\text {linear. }}$.

\begin{tabular}{|c|c|c|c|c|c|}
\hline Guest & $\mathrm{LiCl}$ & $\mathrm{NaCl}$ & $\mathrm{KCl}$ & $\mathrm{RbCl}$ & $\mathrm{CsCl}$ \\
\hline C5 & & - & & - & - \\
\hline $\mathrm{d}_{\mathrm{N}-\mathrm{O}}[\AA]^{[\mathrm{a}]}$ & 6.6118 & - & 5.6616 & - & - \\
\hline Compression $^{[b]}$ & $11.53 \%$ & - & $24.3 \%$ & - & - \\
\hline C4 & - & & & & \\
\hline$d_{N-O}[\AA ̊]^{[a]}$ & & 3.5394 & 4.4581 & 4.6328 & 5.0156 \\
\hline Compression $^{[\mathrm{b}]}$ & & $43.06 \%$ & $28.28 \%$ & $25.47 \%$ & $17.87 \%$ \\
\hline C3 & & & & - & \\
\hline$d_{N-O}[\AA \AA]^{[a]}$ & 3.8315 & 3.3038 & 3.2313 & - & 4.2870 \\
\hline Compression $^{[\mathrm{b}]}$ & $22.70 \%$ & $33.35 \%$ & $34.81 \%$ & - & $13.51 \%$ \\
\hline C2 & & & & & \\
\hline $\mathrm{d}_{\mathrm{N}-\mathrm{o}}[\AA]^{[a]}$ & 3.1179 & 3.0279 & 3.1459 & 3.1670 & 3.1579 \\
\hline Compression $^{[b]}$ & $15.76 \%$ & $18.19 \%$ & $15 \%$ & $14.13 \%$ & $14.68 \%$ \\
\hline
\end{tabular}

We mostly noticed the presence of broad signals in ${ }^{1} \mathrm{H}-\mathrm{NMR}$ spectra of the guest molecules enclosed within p-sulfonatocalix [4]arene host. However in several cases, sharp signals have been observed, but any clear correlation can be established between coupling constants obtained in solution and torsion angles measured in the solid state structures (Table 6S). This is 
reminiscent with dynamic conformational equilibria of the confined guest with $\mathrm{p}$-sulfonatocalix[4]arene host or with fast exchanges of the guest molecules in solution.

This contribution adds several new behaviours to the systematic rationalization and prediction of hydrophobic clustering in the p-sulfonatocalix[4]arene. Overall, these studies may provide new knowledge for understanding the dynamics and adaptivity of complex molecules under confined conditions, reminiscent of the specific binding of substrates in biological pockets.

\section{Acknowledgements}

This work was conducted within NSFC (National Natural Science Foundation of China, 21720102007), China. S.-P. Z. wishes to thank China Scholarship Council for the financial support. This work was also supported by Agence Nationale de la Recherche ANR-15-CE29-0009 DYNAFUN and 1000 Talent Plan, WQ20144400255 and 111 project 90002-18011002 of SAFEA, China.

\section{Conflict of Interest}

The authors declare no conflict of interest.

Keywords: amino acids - calixarenes - hydrogen bonding molecular recognition $\cdot$ self-assembly

[1] J. Voskuhl, B. J. Ravoo, Chem. Soc. Rev. 2009, 38, 495-505.

[2] a) K. D. Daze, F. Hof, Acc. Chem. Res. 2013, 46, 937-945; b) D.-S. Guo, Y. Liu, Acc. Chem. Res. 2014, 47, 1925-1934.

[3] a) R. E. McGovern, H. Fernandes, A. R. Khan, N. P. Power, P. B. Crowley, Nat. Chem. 2012, 4, 527-533; b) R. E. McGovern, A. A. McCarthy, P. B. Crowley, Chem. Commun. 2014, 50, 10412-10415; c) A. M. Doolan, M. L. Rennie, P. B. Crowley, Chem. Eur. J. 2018, 24, 984-991; d) R. E. McGovern, B. D. Snarr, J. A. Lyons, J. McFarlane, A. L. Whiting, I. Paci, F. Hof, P. B. Crowley, Chem. Sci. 2015, 6, 442-449; e) M. Selkti, A. W. Coleman, I. Nicolis, N. Douteau-Guevel, F. Villain, A. Tomas, C. Rango, Chem. Commun. 2000, 161-162; f) L. Memmi, A. Lazar, A. Brioude, V. Ball, A. W. Coleman, Chem. Commun. 2001, 2474-2475; g) A. Hogeweg, A. Sowislok, T. Schrader, C. Beuck, Angew. Chem. Int. Ed. 2017, 56, 1475814762; h) D. Bier, S. Mittal, K. Bravo-Rodriguez, A. Sowislok, J. Briels, C. Heid, M. Bartel, B. Wettig, L. Brunsveld, E. Sanchez-Garcia, T. Schrader, C.
Ottmann, J. Am. Chem. Soc. 2017, 139, 16256-16263; i) T. Schrader, G. Bitan, F.-G. Klärner, Chem. Commun. 2016, 52, 11318-11334.

[4] S. Shinkai, S. Mori, T. Tsubaki, T. Sone, O. Manabe, Tetrahedron Lett. $1984,25,5315-5318$.

[5] a) F. Perret, A. N. Lazar, A. W. Coleman, Chem. Commun. 2006, 24252438; b) F. Perret, A. W. Coleman, Chem. Commun. 2011, 47, 7303-7319.

[6] a) L. A. C. Trembleau, J. Rebek Jr., Science 2003, 301, 1219-1220; b) R. J. Hooley, H. Van Anda, J. Rebek Jr., J. Am. Chem. Soc. 2007, 129, 1346413473; c) R. J. Hooley, J. V. Gavette, M. Mettry, D. Ajami, J. Rebek Jr. Chem. Sci. 2014, 5, 4382-4387; d) A. Asadi, D. Ajami, J. Rebek, Jr. J. Am. Chem. Soc. 2011, 133, 10682-10684.

[7] a) B. C. Gibb, in Organic Nanostructures, Eds. J. L Atwood. and J. W. Steed, Wiley-VCH, 2008, pp. 291-304; b) H. Y. Gan, B. C. Gibb, Chem. Commun., 2012, 48, 1656-1658; c) S. M. Liu, D. H. Russell, N. F. Zinnel B. C. Gibb, J. Am. Chem. Soc. 2013, 135, 4314-4324; d) C. L. D. Gibb, B. C. Gibb, Chem. Commun. 2007, 1635-1637; e) C. L. D. Gibb, B. C. Gibb, J. Am. Chem. Soc. 2006, 128, 16498-16499.

[8] a) F. Kotzyba-Hibert, J. M. Lehn, K. Saigo, J. Am. Chem. Soc. 1981, 103, 4266-4268; b) K. Baek, Y. Kim, H. Kim, M. Yoon, I. Hwang, Y. H. Ko, K. Kim, Chem. Commun. 2010, 46, 4091-4093.

[9] D. G. Dumitrescu, W. X. Feng, Y.-M. Legrand, A van der Lee, E. Petit, M. Barboiu, CrystEngComm 2018, 20, 261-270.

[10] a) Y. M. Legrand, A. van der Lee, M. Barboiu, Science 2010, 329, 299-302; b) Y. M. Legrand, A. Gilles, E. Petit, A. van der Lee, M. Barboiu, Chem. Eur. J. 2011, 17, 10021-10028; c) S. Lee, E. Kapustin, O. M. Yaghi, Science $2016,353,808-811$

[11] a) W. Xiao, C. Hu, M. D. Ward Cryst. Growth \& Des. 2013, 13, 3197-3200; b) Y. Liu, M. D. Ward, Cryst. Growth Des. 2009, 9, 3859-3861.

[12] a) S. J. Dalgarno, J. L. Atwood, C. L. Raston, Chem. Commun., 2006, 4567-4574; b) J. L. Atwood, L. J. Barbour, M. J. Hardie, C. L. Raston, Coord. Chem. Rev. 2001, 222, 3-32; c) J. L. Atwood, T. Ness, P. J. Nichols, C. L. Raston, Cryst. Growth Des. 2002, 2, 171-176; d) K. Suwinska, E. Janneau, Y. Tauran, A. W. Coleman, J. Inclusion Phenom. Macrocyclic Chem. 2014, 79, 177-183; e) A. Lazar, E. Da Silva, A. Navaza, C. Barbey, A. W. Coleman, Chem. Commun. 2004, 19, 2162-2163.

[13] a) W. Feng, L. Dai, S.-P. Zheng, A. van der Lee, C.-Y. Su, M. Barboiu Chem. Commun. 2018, 54, 9738-9740; b) M. Barboiu, D. Dumitrescu, E. Petit, Y.-M. Legrand, A. van der Lee, Cryst. Growth Des. 2015, 15, 35253531.

[14] a) D. Dumitrescu, Y.-M. Legrand, E. Petit, A. van der Lee, M. Barboiu, Chem. Commun. 2014, 50, 14086-14088; b) D. Dumitrescu, Y.-M Legrand, E. Petit, A. van der Lee, M. Barboiu, Chem. Sci. 2015, 6, 2079 2086; c) D. Dumitrescu, F. Dumitru, Y.-M. Legrand, E. Petit, A. van der Lee, M. Barboiu, Org. Lett. 2015, 17, 2178-2181.

[15] CCDC 11981763-1981792 contains the supplementary crystallographic data for this paper. These data can be obtained free of charge from The Cambridge Crystallographic Data Centre. a) J. L. Atwood, F. Hamada, K. R. Robison, G. W. Orr, R. L. Vincent, Nature 1991, 349, 683-684; b) K. Fucke, K. M. Anderson, M. H. Filby, M. Henry, J. Wright, S. A. Mason, M. J. Gutmann, L. J. Barbour, C. L. Oliver, A. W. Coleman, J. L. Atwood, J. A. K. Howard, J. W. Steed, Chem. Eur. J. 2011, 17, 10259-10271.

Manuscript received: March 23, 2020

Accepted manuscript online: March 28, 2020 


\title{
FULL PAPERS
}

Flexible guests: Molecular recognition of cationic $1, \omega$-diammoniumalkanes and $1, \omega$-amino-acids of variable lengths within $p$-sulfonatocalix[4]arene hosts sheds light on the constitutional adaptivity of flexible folded chains by maximizing multivalent contacts with the host receptor under confinement. A comprehensive screening of 30 single-crystal structures allowed the accurate determination of the folded guest molecules structures under confinement.

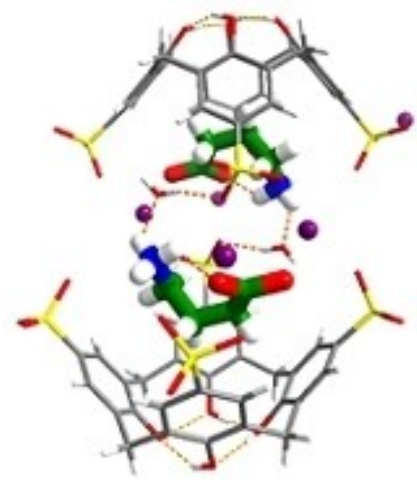

L. Dai, Dr. W.-X. Feng, S.-P. Zheng, Dr. J.-J. Jiang, Dr. D. Wang, Dr. A. van der Lee, D. Dumitrescu, Dr. M. Barboiu*

$1-10$

Progressive Folding and Adaptive Multivalent Recognition of Alkyl Amines and Amino Acids in p-Sulfonatocalix[4]arene Hosts: Solid-State and Solution Studies

Report by@MihailBarboiu et al. @umontpellier@CNRS on progressive folding and adaptive multivalent recognition of alkyl amines and amino acids in p-sulfonatocalix[4]arene hosts both in solution and the solid state

Share your work on social media! ChemPlusChem has added Twitter as a means to promote your article. Twitter is an online microblogging service that enables its users to send and read short messages and media, known as tweets. Please check the pre-written tweet in the galley proofs for accuracy. If you, your team, or institution have a Twitter account, please include its handle @username. Please use hashtags only for the most important keywords, such as \#catalysis, \#nanoparticles, or \#proteindesign. The ToC picture and a link to your article will be added automatically, so the tweet text must not exceed 250 characters. This tweet will be posted on the journal's Twitter account (follow us @ChemPlusChem) upon publication of your article in its final (possibly unpaginated) form. We recommend you to re-tweet it to alert more researchers about your publication, or to point it out to your institution's social media team.

\section{ORCID (Open Researcher and Contributor ID)}

Please check that the ORCID identifiers listed below are correct. We encourage all authors to provide an ORCID identifier for each coauthor. ORCID is a registry that provides researchers with a unique digital identifier. Some funding agencies recommend or even require the inclusion of ORCID IDs in all published articles, and authors should consult their funding agency guidelines for details. Registration is easy and free; for further information, see http://orcid.org/.

\author{
Liya Dai \\ Dr. Wei-Xu Feng \\ Shao-Ping Zheng \\ Dr. Ji-Jun Jiang \\ Dr. Dawei Wang \\ Dr. Arie van der Lee \\ Dan Dumitrescu \\ Dr. Mihail Barboiu http://orcid.org/0000-0003-0042-9483
}

